\title{
Blood Donor Information System Design Based on Web (Case Study in Pmi Tasikmalaya)
}

\author{
Rian Arie Gustaman ${ }^{1}$, Eka Wahyu Hidayat ${ }^{2}$ \\ ${ }^{I}$ Faculty of Health Sciences, University of Siliwangi Tasikmalaya, Indonesia \\ rianarie@unsil.ac.id \\ ${ }^{2}$ Faculty of Engineering, University of Siliwangi Tasikmalaya, Indonesia \\ ekawahyueunsil.ac.id
}

\begin{abstract}
Based on the fact, that the Indonesian Red Cross (PMI) Tasikmalaya have similar problems with other Red Cross branches, especially in the Blood Donor Unit. The problem is still using manual processing and the lack of data integration between the PMI to the Hospital Blood Bank (BDRs) so that one of the factors degrading the quality of service to patients. Information technology can be one of the solutions in managing data between PMI and BDRs. The method in this study is what, who, where, when, why, how (5W1H) by the method of application development is the Extreme Programming (XP) is restricted to the stages Planning and design stages. SMS gateway is involved in blood donor service system, making it easier for patients to get blood data information. The results of this research is the application of Transaction Processing System (TPS) and SMS gateway running according to plan. At the stage of planning and design stages of the method of XP (Extreme Programming) involves a lot of admin and user (patient). SMS gateway technology allows patients to obtain the desired blood stock information. Duration of privileges by the patient should be limited based on the authority of a doctor.
\end{abstract}

Keywords — Information System, Blood donors, PMI

\section{INTRODUCTION}

Implementation blood service is obligatory under the authority of local government according to Law 32/2004, particularly in Tasikmalaya [3]. Tasikmalaya city has been proclaimed as a donor in 2013 and is targeted to be blood barn in West Java in 2015 [4]. Blood is a national asset that only the Indonesian Red Cross (PMI) has the right to manage it, while BDRs Hospital is a unit that receives and stores blood from UTD for Hospital services needs [1]. Blood transfusions are a part of health care should have the assurance that blood products must be safe, healthy, clinically effective and quality. Safety of blood intended for patients, donors, staff and the community.

PMI information management in Tasikmalaya in serving patients of blood donors has not been using information technology, whereas WAP technology can be utilized to build a blood donor service information system [2], [5]. As a result of the lack of application of information technology, the number of issues including the lack of public awareness on blood donation, blood stocks difficulty of obtaining information both in the BDRs and in PMI, and high patient doubt on the quality of the blood in the PMI. Application of information technology at the blood donor service system will provide benefits for donors include the historical data recorded their details and can be accessed anytime [6].

This study is an initial stage of development of blood donor information system with the adoption of Extreme Programming [7]. Understanding the business flow into the main target of this research, in order to obtain the system requirements and corresponding business flow. SMS gateway technology is a technology that will be applied to the design of the system.

\section{Research Methodology}

This study uses a model approach $5 \mathrm{~W} 1 \mathrm{H}$ investigation (what, who, where, when, why, how). This approach is to formulate and to find the root of existing problems in Tasikmalaya PMI in order to obtain a draft proposal of the application system as the final solution of this study. The approach in the development of software used is the Extreme Programming (XP) with four stages, namely Planning, Design, Coding, Testing. In this study two preliminary stages are done in the software engineering process. Planning stages that intersect with stage $5 \mathrm{~W} 1 \mathrm{H}$ useful to get proper planning and complete for the blood donor service information system that will be built, as in the following figure. 


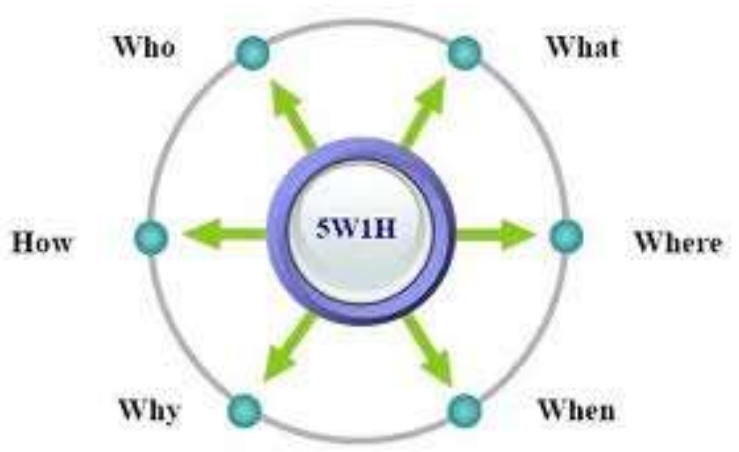

Fig 1. Research Approach

At the stage of Design performed the software engineering process using Functional Modeling and Data Modeling. Functional modeling is used to design and see the extent of the application to be made can be used in accordance with the needs in the field. While Data modeling is done to see what data is needed to build the information system application services blood donor. In this modeling has identified the need for data to support the application Transaction Processing System (TPS) and the data required to support the application of SMS Gateway system. At this stage, also designed the architecture of the global system for blood donor service information system.

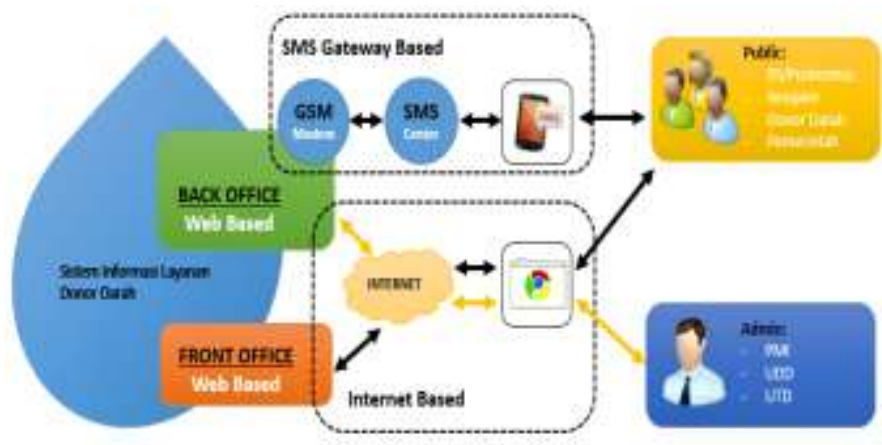

Fig 2. System Architecture

The approach used in engineering applications using ToolsUWE functional modeling (UML-based Web Engineering). ToolsUWE a methodological approach to the development of web applications that are determined by the notation UML (Unified Modeling Language). While UML is one of the object-oriented modeling language fairly well.

\section{RESULT AND DisCUSSION}

In this modeling has been successfully identified actors involved, namely Administrator Actorand User Actor. Administrator Actoris an individual whose role in the management of the overall system better linkages with users of the system and data. Users are individual actors can only see the data provided by the expert system. In this study has also successfully determined Use Case for main system consisting of 48 use-case with global UseCase Diagram as follows:

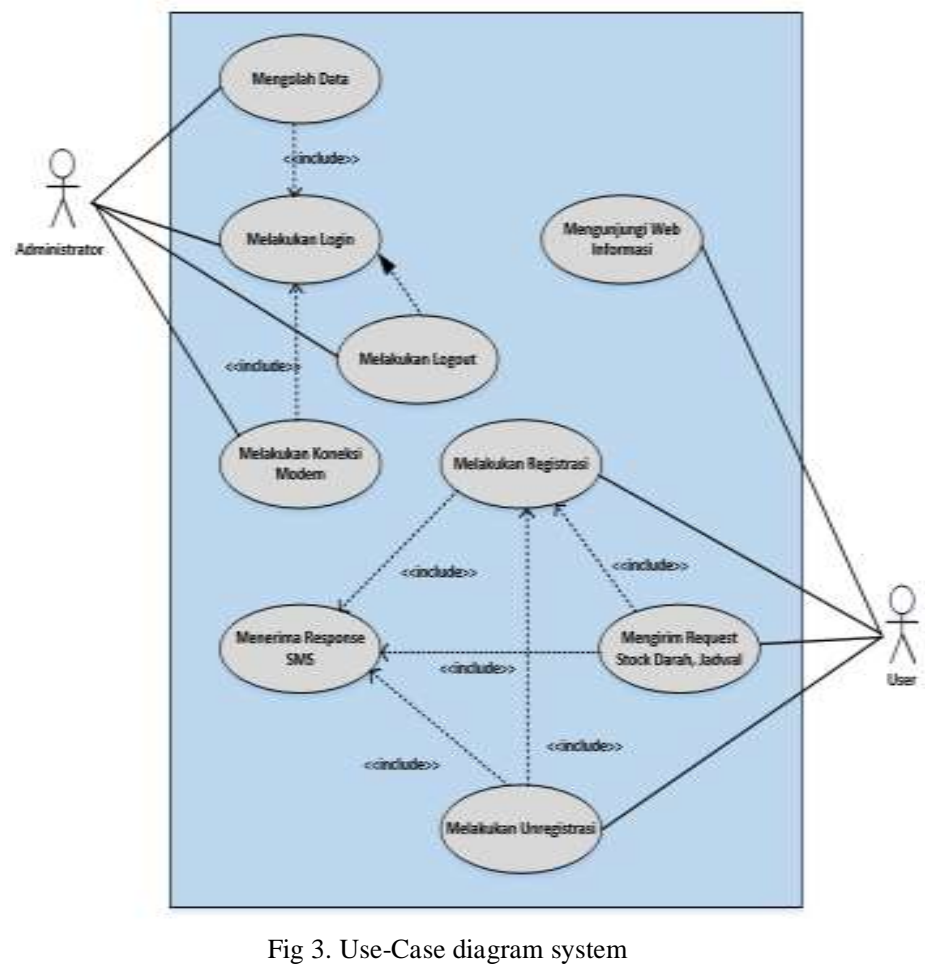

At the stage of Design, has also produced a draft Sequence Diagram illustrating the interactions between objects inside and outside applications Transaction Processing System. Because the system is built very large then made two key design of sequence diagrams for Transaction Processing System (TPS) and SMS Gateway System as shown in Figure 4 and Figure 5. 

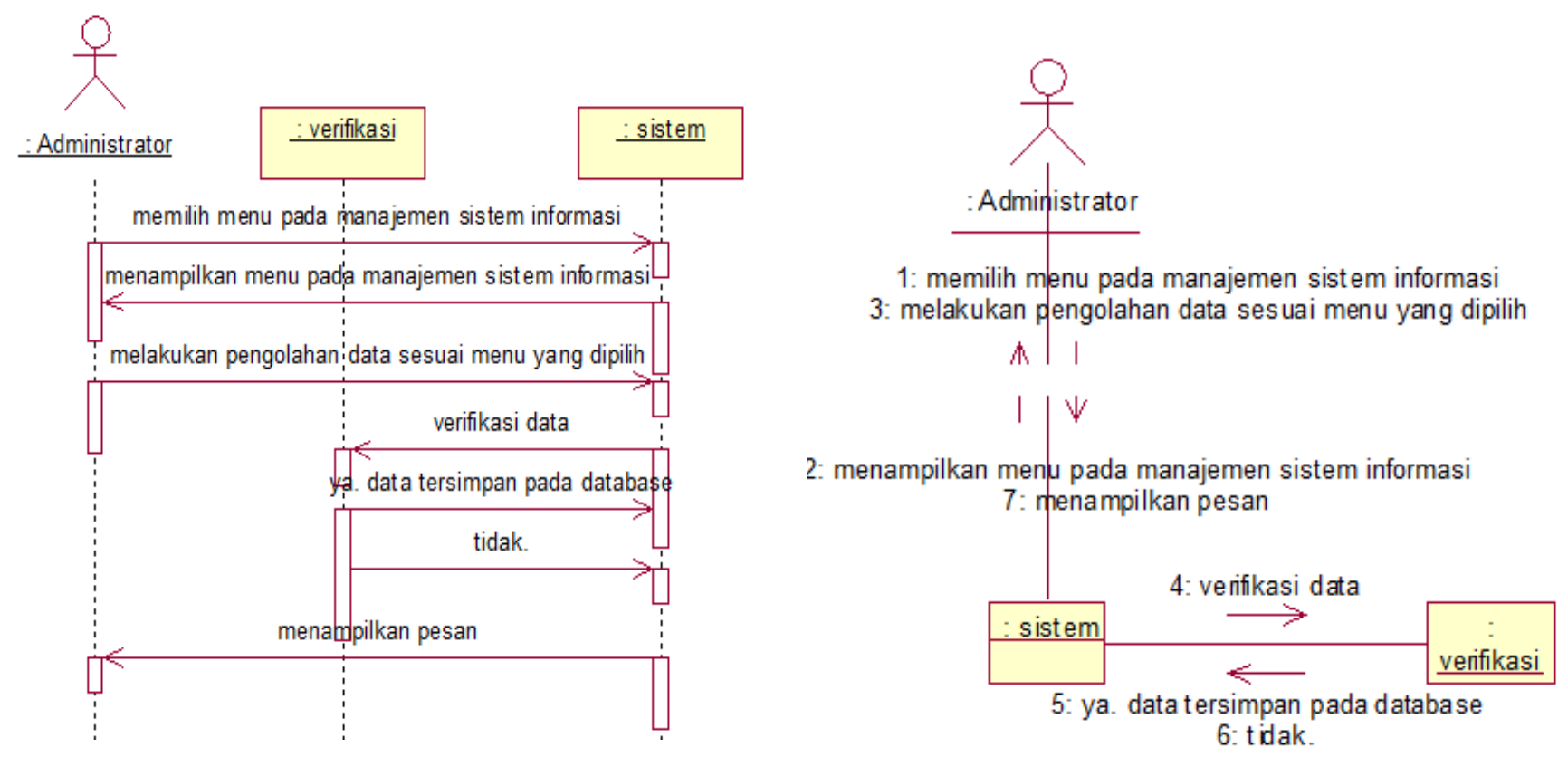

Fig 4. Sequence diagram TPS

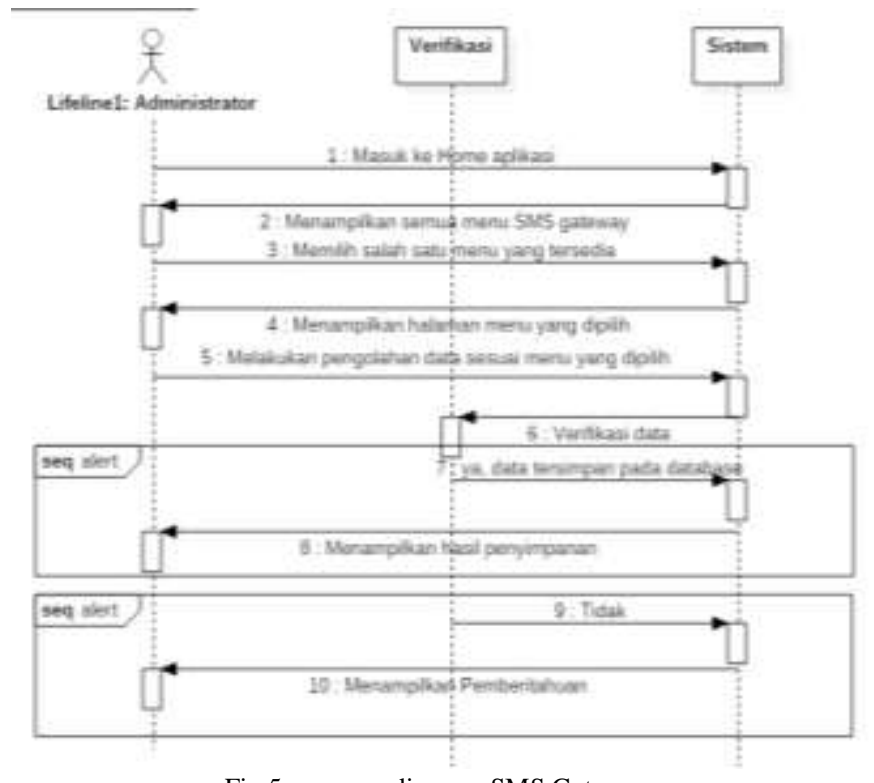

Fig 5. squence diagram SMS Gateway

As with sequence diagrams, Collaboration diagrams also describe the interactions between objects, but more emphasis on the role of each object and not on time delivery of messages. The following collaboration diagram that corresponds to 6: tidak.

Figure 6. Collaboration diagram TPS

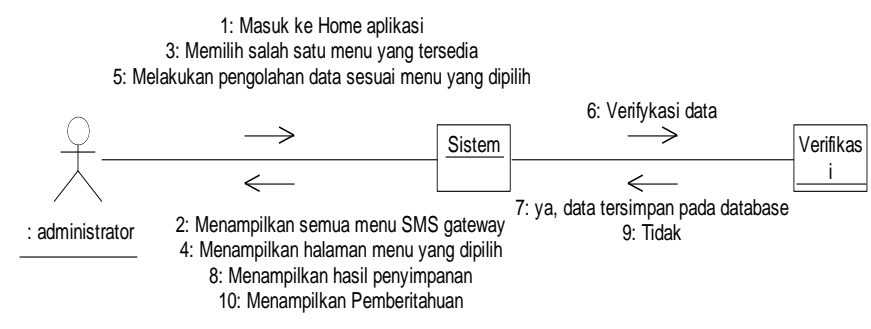

Fig 7. Collaboration diagrams SMS Gateway

Activity flow diagram illustrates various activities in the application Transaction Processing System (TPS), from start to flow starts, decision that might occur, and how they ended. Activity diagrams can also illustrate the parallel processes that may occur in several executions. Activity diagram is a special state diagram, where most of the action and the state is largely a transition triggered by the expiration of the previous state (internal processing). The following activity diagram that is generated. the existing sequence diagram. 


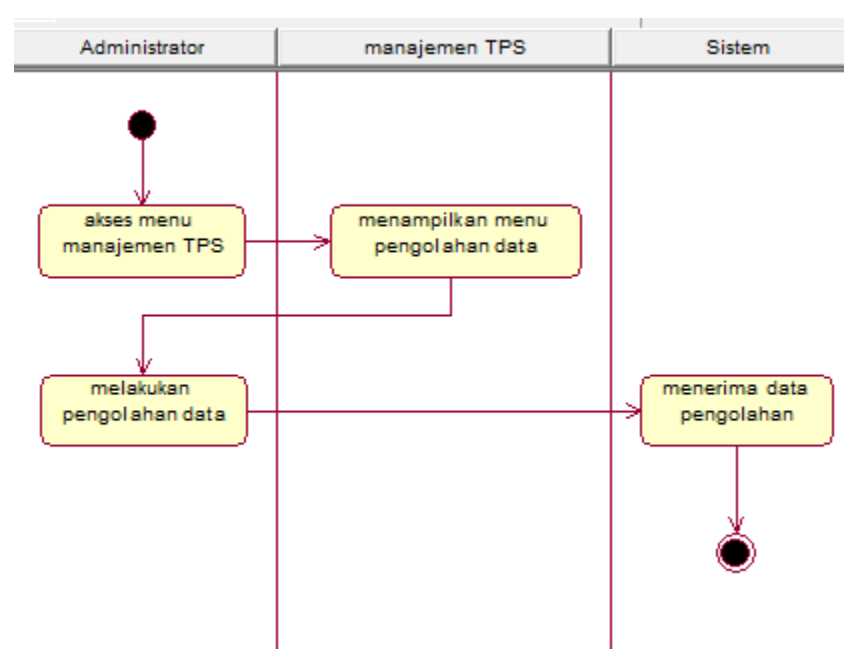

Fig 8. Activity diagram TPS management

Modeling datais the process used to define and analyze data requirements needed to support the business processes within the scope of the appropriate information systems organization. Modeling dataprocess involving professional data modelers who work closely with business stakeholders, as well as potential users of the information system. At the beginning of the data requirements are recorded as a conceptual data model which is a set of specifications independent technology and data used to discuss the initial needs with business stakeholders. The conceptual model is then translated into a logical data model. This logical data model can document the structure of the data that is implemented in the database.

In general, the data needs required in the application of information system services blood donor in PMI Tasikmalaya divided into two aspects of technology that needs the data for TPS and the data required for the SMS Gateway system. Data requirements for TPS obtained from the process of requirements gathering data in the field is DonorsData, Patient ReferralData, Admission Donors, Feasibility Blood Donor, Aftap, Screening Management Pouch Blood, Demand Blood, Inspection Blood, Cross Match, Comb Test, Screening Antibodies, Submission, List Combo Test, Acceptance Blood Grants, Stock Early Blood, Destruction Asset Blood, Stock Taking, Blood, Master Data Institute, Master Data type Pouch Blood, HB level Master data, WorkMaster Data, DiseaseMaster Data, Blood productsMaster Data,
UTDProfile, RhesusMaster Data, Time DonorMaster Data, Type TestMaster Data, Ward Hospital Master Data, Type of RequestMaster Data, Indications Blood transfusionMaster Data, HospitalMaster Data, DoctorsMaster Data, and Events data. As for the SMS Gateway system takes data following Send SMS, SMS Outbox, Inbox SMS, Credit Checks, Sent Items, Contacts, Phonebook Group, User.

From the test results of the prototype application that gained TPS applications for front office and back office has been tested on the local network and provides output in the form of reports on the results of data processing in accordance with the purpose and function of the application is for daily operations. While SMS Gateway application has been tested with the result that the application has successfully met / leave a response of each request with a specific code of the SMS sent by the user. SMS Application Gateway also give response to all requests by the wrong code. Overall both the application complies with functionality.

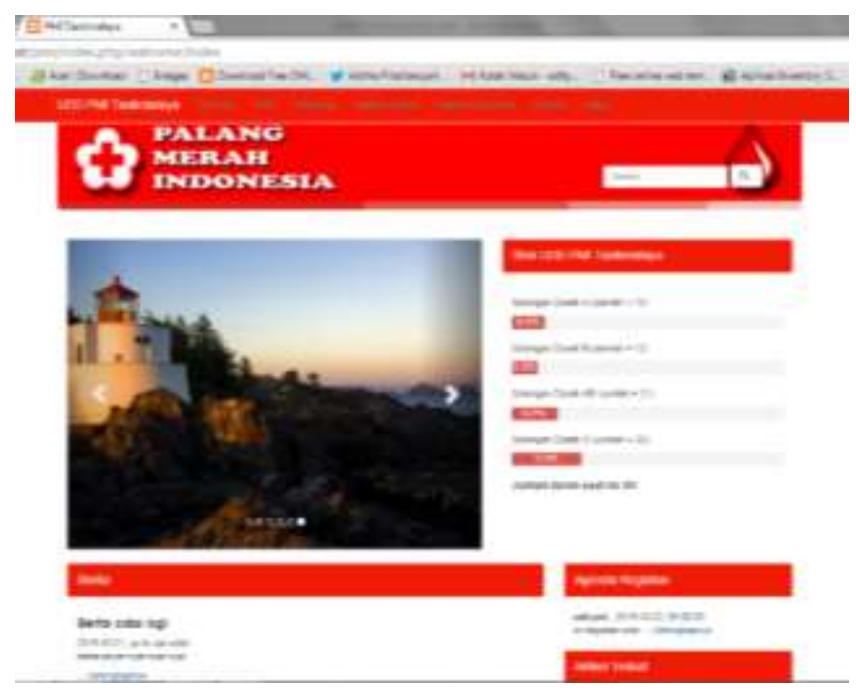

Fig 9. Display prototype Front Office TPS 


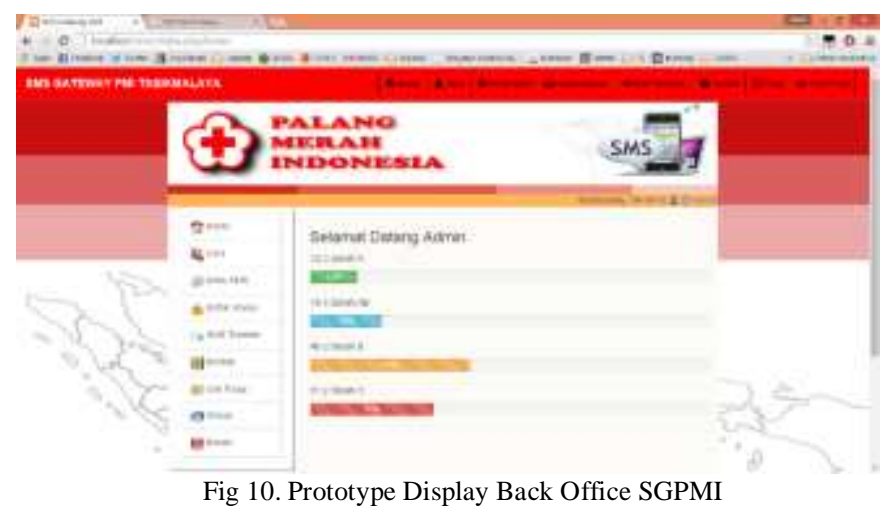

From a series of tests on both systems has been in line with expectations to be desired in terms of application design. Blood Donors for TPS system, the system prototype has been used as of the hope, namely for data management.

In this research, data collection and discussion on topics that are at issue. Software development that is chosen is XP (Extreme Programming) is an object-oriented approach. Of the four stages in XP, namely Planning, Design, Coding and Testing. In accordance with the outcomes to be achieved in the first year of study, the stage that has been done is the Planning and Design.

In the Planning stage of data collection using $5 \mathrm{~W}+1 \mathrm{H}$ approach to look at the root causes and to collect data on PMI Tasikmalaya. At the stage of Design performed the software engineering process using Functional Modeling and Data Modeling. Functional modeling is used to design and see the extent of the application to be made can be used in accordance with the needs in the field. The approach used in engineering applications using ToolsUWE functional modeling (UML-based Web Engineering). ToolsUWE a methodological approach to the development of web applications that are determined by the notation UML (Unified Modeling Language). While UML is one of the object-oriented modeling language fairly well. The success of this model is identified actor who will use the application, determined and created Use Case Use-Case Diagram. While Data modeling is done to see what data is needed to build the information system application services blood donor. In this modeling has identified the need for data to support the application of information systems and the data required to support the application of SMS Gateway system.

\section{CONCLUSIONS}

The conclusion of this study is the application made by the method of XP (Extreme Programming), the Application Transaction Processing System (TPS) and SMS Gateway Applications that involve a lot of admin and user (patient). SMS gateway technology allows patients to obtain the desired blood stock information. Duration of privileges by the patient should be limited based on the authority of a doctor.

\section{ACKNOWLEDGMENT}

In the Name of Allah, the most Gracious, the most Merciful All praises be to Allah, king of the king, the Lord of the world, and the master of the day after, who has given us blessing and guidance. Because of His graciousness and mercifulness the writer can write well. The writer realizes and feels very sure that without His blessing, mercy, and guidance, it would be possible for himself to finish the paper.

The researcher presents his sincere appreciation goes to Prof.DR.Rudi Priyadi the rector of siliwangi university Tasikmalaya, All lectures in University Siliwangi and his very sincere thanks to who are not mentioned personally here, without their patience, guidance, support and cooperation this paper could have never been written.

\section{REFERENCES}

[1] Adisasmito. Wiku. 2008. Rancangan Peraturan Pemerintah tentang Pelayanan Darah. Universitas Indonesia

[2] Maryanto. 2010. Sistem Informasi Layanan Donor Darah Berbasis Wap. UGM Yogyakarta.

[3] http://www.republika.co.id/berita/regional/jawabarat/11/12/02/lvkkzmyayasan-setara-endus-mafia-darah-di-udd-pmi-tasikmalaya

[4] http://www.pikiran-rakyat.com/node/192837 2013.

[5] Kulshreshtha Vikas. 2011. Blood Bank Management Information System in India. ISSN: 2248-9622. Vol. 1, Issue 2, pp.260-263. India

[6] Kulshreshtha Vikas . 2011. Benefits of Management Information System in Blood Bank. International Journal Of Engineering And Science ISSN: 2278-4721, Vol. 1, Issue 12(December 2012), PP 05-07. India

[7] Pressman, 2010. Software Engineering: A Practitioner's Approach. the seventh edition. 